\title{
Knowledge Based Engineering for Hydrogen Gas Turbines and Burners Design: a review
}

\author{
Corallo Angelo ${ }^{1}$, Dibiccari Carla $^{1}$, Lazoi Mariangela ${ }^{1, *}$ Starace Giuseppe ${ }^{2}$ and Laforgia Domenico ${ }^{1}$, \\ ${ }^{1}$ Dipartimento di Ingegneria dell'Innovazione, Università del Salento, via per Monteroni, sn., 73100, Lecce (LE), Italy \\ ${ }^{2}$ Dipartimento di Management, Finanza e Tecnologia, Università LUM, km 18 SS.100, 70019 Casamassima (BA), Italy
}

\begin{abstract}
Hydrogen gas turbines and burners need high attention and their appropriate realization, yet during their design, can lead important benefits for the whole sector. Realizing the best design, the first time, reduces reworks and requests of design changes from the manufacturing departments. In this field, Knowledge Based Engineering is a good strategy for embedding, in an automatic way, experts' knowledge into CAD models during the design of a component. It enables a reduction of human errors and costs in several design tasks and improving the final quality of a component model. With these premises, the aim to the study is to lead improvements and appropriate actions in the design and re-configuration of hydrogen power generation systems (i.e. gas turbines and burners) by means of KBE, leading improvements yet in this early phase of the global race for hydrogen. A systematic literature review is carried out to explore the current state of art for the application of KBE for the design of turbines and burners in different industrial sectors. Evidences from the practice are collected in a structured classification and elaborated and summarized for application in the design of gas turbines and burners for the hydrogen production.
\end{abstract}

\section{Introduction}

Researches on hydrogen power generation systems (HPG) systems currently play a relevant role in assuring appropriate levels of productivity and sustainability. Compared to power generation based on traditional hydrocarbon fuels, HPG systems, coupled with the use of renewable energy sources for hydrogen production, could dramatically reduce greenhouse gases emissions, relying on a completely $\mathrm{CO} 2$ free energy source [1].

The major global industrial players in power generation, like GE Power [2], Mitsubishi Power [3] and Ansaldo Energia [4], are dealing with the conversion of traditional gas turbines to the combustion of mixed-fuel. The challenges of this transition are mostly related to the specific combustion characteristics of high hydrogen fuels. A new configuration of the fuel accessory system is, thus, needed in order to adjust the traditional gas turbines for hydrogen flow rates. The sealing systems should be reconsidered and replaced with welding or other specifically designed components. For example, the combustor component should be adapted for preventing flashback issues [2] [3] [5].

Gas turbines and burners are key components of HPG systems. They are products resulting by the assembly of different components that are specified through dimensional and geometrical values to guide their physical realization. Variations in the components can lead to problem in the assembly requiring re-works of parts with higher costs for a company. Accurately design the product, its physical elements and how to assembly them in a main architecture, it's a critical activity for avoiding changes during the manufacturing where reworks and stops require higher cost. Computer aided design (CAD) systems supported by other CAX technologies (Computer Aided Technologies) to define engineering, manufacturing or testing data are used during the design. CAD is referred to the math-based definition of the physical architecture of the product and can use two-dimensional (i.e. an engineering drawing with geometrical and dimensional values) or three dimensional space (i.e. a solid model for virtual test and analysis) to define and allocate the product and the elements shapes [6].

In Computer-aided technologies (CAx) systems, Knowledge Based Engineering (KBE) covers a relevant role. It is related to the application of knowledge to automate or assist the engineering tasks [7]. KBE can be integrated in $\mathrm{CAD}$ software for capturing engineering knowledge and for integrating the entire design process in a single data model [8]. According to Yao et al. [9], KBE supports the designers by decreasing the repeated design work, that represent about $80 \%$ of engineering activity [10] [11]. It automates the non-creative and repetitive tasks in the design phase by integrating multidisciplinary concepts [12].

In the current state of art, a study providing guidelines for improving the design of hydrogen power generation components with KBE is currently missing. This paper

\footnotetext{
* Corresponding author: mariangela.lazoi@, unisalento.it
} 
aims to reduce this gap extending the discussions of the relevance of an appropriate design also to the hydrogen field considering KBE as a relevant method to support it. A systematic literature review is carried out on papers published on the topic of $\mathrm{KBE}$ for turbine and burners design.

From the analysis of the papers, evidences from the practice are collected in a set of insights highlighting type of product, type of KBE, managed issues and benefits. These contents are then elaborated and summarized in a set of guidelines applicable in the design of gas turbines and burners for the hydrogen production.

Industrial practioners can benefit from this study for leading their design and configuration activities introducing innovations and best practices from others industrial fields while academia researchers can consider this study as a main reference for defining future researches.

\section{KBE Overview}

Very often companies launch new products that are evolutions of existing products, re-applying components and engineering techniques in multiple designs. In these cases, the new product development process can lead to sub-optimal use of company knowledge, devoting hours of work by highly experienced designers to activities of little value, like routine calculation, part catalog browsing and update of $\mathrm{CAD}$ models. $\mathrm{KBE}$ is able to automate routine engineering tasks, allowing the reduction of the design cycle and the engineers to spend time and resources on creative tasks. Therefore, considering the definition of La Rocca [13], "KBE is a technology based on the use of dedicated software tools that can capture and reuse product and process engineering knowledge." Two main features enable KBE to achieve its goals of reducing time and costs in new product development: "automation of repetitive and non - creative design task; and support of multidisciplinary design optimization in all the phases of the design process » [13].

KBE systems are implemented as software environments that tightly integrate an object-oriented programming component in a geometric modelling tool [13 - 14]. KBE leverages the parametric modelling feature used by mechanical CAD allowing generative modelling. In generative modeling, design requirements are encoded in computer readable rules, enabling design automation. Moreover, thanks to KBE, CAD objects are enriched with information that can optimize decisions and changes along the lifecycle of the product. Specific skills are required to create $\mathrm{KBE}$ applications in these environments and a new, dedicated figure emerged: the $\mathrm{KBE}$ engineer. $\mathrm{KBE}$ applications developed by KBE engineers can be applied by different company's roles, like designers and product managers, in their daily activities [15].

Several benefits are associated with KBE: 1) $K B E$ improves product quality. Appling $\mathrm{KBE}$ to the product development process leads to a dramatic increase of the overall products' quality. Task automation can remarkably increase the number of design and simulation iterations. Embedding computer rules to design can avoid possible design mistakes or detect errors more easily and in the earlies design phases. Moreover, KBE decodes and stores designers experience, making it more effective [16]. This consideration leads to a second particular benefit of KBE.

2) $K B E$ gathers engineering expertise and supports knowledge reuse. KBE applications are containers of engineering knowledge which is formally translated in rules and algorithms. The particular development process of a KBE application involves an experienced designer describing his activities in terms of functional requirements which are then translated in design rules and software functionalities. The KBE application can be then used by less experienced designers allowing the experienced resources to focus on high-end design activities.

3) $K B E$ allows to reduce design cost. Most of a product's lifecycle cost is determined in the earliest design phases. Decisions and trade-off considerations taken as early as the preliminary design stage commit between 60 $\%$ and $80 \%$ of the final cost [17]. Exploring multiple design alternatives would limit cost compromises identifying optimum solutions for design parameters and cost at once. Design alternatives are often produced and testes through a chain of repetitive, time-consuming CAxbased tasks, leading designers to develop only a limited amount of design solutions and settle for a non-optimal one. Considering KBE in the design process allows the production and the evaluation of a high number of design solutions in a short time, using automation and enriching design models with knowledge.

4) KBE enables Concurrent Engineering. It is a paradigm of product development based on the notion of performing simultaneously and collaboratively tasks that were usually performed in sequence and individually by different disciplinary teams [14]. KBE environments provide specific functionalities for setting up collaboration on a product model. Rule and constraint setting for each discipline, change management, change detection, model checking and update functionalities allows for consistent collaboration during design.

It is important to note, however, that when applying KBE design tasks should be carefully chosen. A number of authors identified a set of cases when KBE would not be convenient $[14,17,18]$. More specifically, Stokes [10] identifies the following situations where the use of $\mathrm{KBE}$ is not appropriate: 1) when the functionality that should be automated using KBE is already offered by CommercialOf-The-Shelf (COTS) applications; 2) if the design processes and products, are highly subject to change; 3 ) when the design processes are blurry and not well defined; 4) if it is not possible to clearly outline and isolate a particular design stage; and 5) when the technology in the design process is constantly changing. 


\section{Research Method}

In order to address KBE issues for Gas Turbines and Burners design, a systematic literature review was carried out. It consisted in a replicable process aimed at guiding decisions, procedures and conclusions [20] in the analysis of the scientific state of art.

Among the different systematic literature review strategies, in this study the strategy suggested by Corallo et al. [21]was adopted. It is composed by four steps:

1. Review Planning. In this step, the objectives are defined, the source of information to be consulted are selected, the search keywords are chosen, the filters for the results are identified, the qualitative mechanism for contents selections are planned, the way to track the reference is defined.

2. Search Execution. During this step, the sources are interrogated with search queries, the results are preliminarily filtered and selected.

3. Documents Analysis. In this step, the selected documents are examined, specific contents, elements and key concepts are detected and the final selection of documents is defined. Furthermore, relationships among papers are compared and a critical analysis of papers contents is done.

4. Results Reporting. In this step, the results are summarized and the consulted reference tracked.

The described steps represent the reference to execute the study with a predefined logical and temporal flow.

\subsection{Papers Selection and Analysis}

According to the described systematic literature review strategy, after the definition of the objective of analysis, the search process starts with a selection of scientific papers. In this study, Scopus (www.scopus. com) was used as main electronic scientific indexed database and all queries were launched on September 2021.

The search criteria and the related results are reported in Table 1.

Table 1. Search criteria and results.

\begin{tabular}{|l|l|l|l|}
\hline ID & \multicolumn{1}{|c|}{ Query } & \#Results & \multicolumn{1}{|c|}{$\begin{array}{c}\text { \#Filtered } \\
\text { Results }\end{array}$} \\
\hline 1 & $\begin{array}{l}\text { Title-Abs-Key("Hydrogen") } \\
\text { And Title-Abs-Key(Kbe) Or } \\
\text { Title-Abs-Key(« Knowledge } \\
\text { Based Engineering ») }\end{array}$ & 5 & 0 \\
\hline 2 & $\begin{array}{l}\text { Title-Abs-Key("Power } \\
\text { Generation System*") And } \\
\text { Title-Abs-Key(Kbe) Or } \\
\text { Title-Abs-Key(« Knowledge } \\
\text { Based Engineering ») }\end{array}$ & 0 & 0 \\
\hline 3 & $\begin{array}{l}\text { Title-Abs-Key("Turbin*") } \\
\text { And Title-Abs-Key("Kbe") } \\
\text { Or Title-Abs- } \\
\text { Key("Knowledge Based } \\
\text { Engineering") }\end{array}$ & 19 & 17 \\
\hline
\end{tabular}

\begin{tabular}{|l|l|l|l|}
\hline 4 & $\begin{array}{l}\text { Title-Abs-Key("Burner*") } \\
\text { And Title-Abs-Key("Kbe") } \\
\text { Or Title-Abs- } \\
\text { Key("Knowledge Based } \\
\text { Engineering") }\end{array}$ & 1 & 1 \\
\hline Total & 25 & 18 \\
\hline
\end{tabular}

To find the most suitable study in the field of analysis, a first query was made on hydrogen and $\mathrm{KBE}$, in order to explore existing studies treating $\mathrm{KBE}$ in the hydrogen field. The result of this query was of five papers but out of scope. In these papers, KBE was treated with different meanings (e.g. Kadanoff-Baym Equations). Another query explored the existence of studies about power generation systems and $\mathrm{KBE}$, but no result was reported. A good number of studies was instead, selected using a third query combining Gas Turbines and KBE. Only two papers were excluded: one was out of scope and the other a replication. The last query, with Burner and $\mathrm{KBE}$, extended the selection of one more paper.

Therefore, 18 papers were considered relevant to the analysis of the KBE role on HPGS design, mainly considering Gas Turbines and Burners. In Table 2, information on the 18 papers are provided.

Table 2. Selected Papers.

\begin{tabular}{|c|c|c|c|c|}
\hline ID & Reference & Type & Year & Country \\
\hline 1 & {$[22]$} & Conference Paper & 2018 & USA \\
\hline 2 & {$[23]$} & Article & 2015 & China \\
\hline 3 & {$[24]$} & Conference Paper & 2015 & Germany \\
\hline 4 & {$[25]$} & Conference Paper & 2014 & China \\
\hline 5 & {$[26]$} & Conference Paper & 2013 & Germany \\
\hline 6 & {$[27]$} & Conference Paper & 2010 & Netherlands \\
\hline 7 & {$[28]$} & Article & 2010 & China \\
\hline 8 & {$[29]$} & Conference Paper & 2007 & USA, \\
\hline 9 & {$[30]$} & Article & 2006 & China \\
\hline 10 & {$[31]$} & Conference Paper & 2001 & USA \\
\hline 11 & {$[32]$} & Article & 2001 & USA \\
\hline 12 & {$[33]$} & Conference Paper & 2000 & USA \\
\hline 13 & {$[34]$} & Conference Paper & 1995 & USA \\
\hline 14 & {$[35]$} & Article & 1994 & USA \\
\hline 15 & {$[36]$} & Article & 1993 & USA \\
\hline 16 & {$[37]$} & Conference Paper & 1993 & USA \\
\hline 17 & {$[38]$} & Conference Paper & 1989 & USA \\
\hline 18 & {$[39]$} & Conference Paper & 2005 & USA \\
\hline & & & & \\
\hline
\end{tabular}

The papers selected in this study were red and the contents analysed comparing similar and different results. In particular, the evaluation of the papers was based on four topics: 1) type of product; 2) type of $\mathrm{KBE}$ solution or approach; 3) managed issues; and 4) benefits.

As a result, a set of insights was defined, collecting the most relevant evidence for leading future research and design applications and decisions. 


\section{Results and Discussion}

The studies available in the current literature exploring $\mathrm{KBE}$ application for gas turbines and burners design are mainly focalized on the aerospace, energy and automotive sectors. As illustrated in table 3, the analyzed papers address many different types of product. In general, they are complex products [40] characterized by high technology value, several customizable parts and high investments.

Table 3. Type of product.

\begin{tabular}{|l|c|}
\hline \multicolumn{1}{|c|}{ Type of Product } & Reference \\
\hline Bulb Turbine & {$[22]$} \\
\hline Combustor & {$[24]$} \\
\hline Airfoils shapes & {$[24,28]$} \\
\hline Rotating Machines & {$[25]$} \\
\hline Turbine Blade & {$[22,27,32$,} \\
\hline Turbine Impeller & {$[29]$} \\
\hline Compressor Rotor and Compressor Blades & {$[30]$} \\
\hline $\begin{array}{l}\text { Micromachined Atomizers (e.g. for gas } \\
\text { turbine engines) }\end{array}$ & {$[31]$} \\
\hline Turbine Engines & {$[33]$} \\
\hline Gas-Turbine Nozzles & {$[34-36]$} \\
\hline Utility Boiler Burners & {$[38]$} \\
\hline
\end{tabular}

The performed KBE solutions, to support the design of the cited product, are of different types. In [23], a KBE interface-tool and a database are implemented, using also automation script based on interface-tool input and database information. Context-sensitive allocation of design-relevant knowledge was realized in [25] for the identification of components of complex machineries. In [27], instead, after the definition of design process and domain knowledge, case-based reasoning is combined with rule-based reasoning, for improving the efficiency in the retrieval of information. Knowledge fusion is also a topic associated to KBE. It is used in [29] for the combination of knowledge and CAD software through a blurry inference mechanism. Neural networks' learning ability and fuzzy's logic are also applied for automatic acquire knowledge in a KBE solution [31] as well as Rule Stream's database architecture [38].

Some papers illustrate the steps for KBE application. Reference [24] describes the steps for the KBE implementation (i.e. structure-behavior function model definition, neural rules deduction, design method establishment, dimensional model set-up, algorithm of geometric parameters proposal) contestualized for the design of airfoils variable pitch wind turbines. In [22], the main steps are also described. They are summarized in 1) knowledge acquisition, 2) knowledge representation, 3) knowledge reasoning, 4) establishment of knowledge base. In this last step, the knowledge base is considerd as a set of experience, rules case and other knowledge applicable in a specific domain. These steps are applied for the selection of the type of bulb turbine generator in the hydraulic field.

For the development of these KBE solutions several issues have been managed related to the design process and the engineers' tasks.

Table 4. Managed Issues.

\begin{tabular}{|l|c|}
\hline \multicolumn{1}{|c|}{ Managed Issues } & Reference \\
\hline Performing several refinement studies & {$[22-23]$} \\
\hline Knowledge Acquisition Bottlenecks & {$[31]$} \\
\hline Long Design Time & {$[22,37]$} \\
\hline Lacking of Expert Experience & {$[27]$} \\
\hline Low Level of Intelligence & {$[27]$} \\
\hline Fuzzy Inferences & {$[29]$} \\
\hline $\begin{array}{l}\text { Reparametrization of scalable products for } \\
\text { family of parts }\end{array}$ & {$[34-36]$} \\
\hline
\end{tabular}

In almost all the papers, benefits are cited and described for the application of KBE solution. They are mainly related to the re-use of experts (design engineers) knowledge that have to be captured and automatized in the solutions. Using KBE, the design quality is increased as well as the efficiency of the realized design that avoids drop backs to the conceptualization phases, increasing the design time. The CAD models are better developed and debugged using in some case minimal source code, independent of proprietary CAD systems. KBE solutions helps to reduce the learning curves for new employees working in the design and manufacturing field; it can enrich the model with information also about why and how activities that have to be performed and choices that have to be taken. A detail of the main reference and associated benefits are available in Table 4.

Table 4. Benefits.

\begin{tabular}{|l|c|}
\hline \multicolumn{1}{|c|}{ Benefits } & Reference \\
\hline $\begin{array}{l}\text { Reduction of the risk of a drop back to } \\
\text { the conceptual phase }\end{array}$ & {$[25]$} \\
\hline $\begin{array}{l}\text { Capture and reuse the expert experience } \\
\text { efficiently }\end{array}$ & {$[27,31,33$,} \\
\hline $\begin{array}{l}\text { Heighten the design efficiency and } \\
\text { quality }\end{array}$ & {$[27,37]$} \\
\hline $\begin{array}{l}\text { Portable web-based development and } \\
\text { runtime environments }\end{array}$ & {$[28]$} \\
\hline $\begin{array}{l}\text { Independence from proprietary CAD } \\
\text { systems }\end{array}$ & {$[28]$} \\
\hline $\begin{array}{l}\text { Automatic caching and dependency } \\
\text { tracking for scalable runtime } \\
\text { performance of large models }\end{array}$ & {$[28]$} \\
\hline Minimal source code volume & {$[28]$} \\
\hline $\begin{array}{l}\text { More efficient, clearer and easier model } \\
\text { development and debugging }\end{array}$ & {$[22,26,28$,} \\
\hline $\begin{array}{l}\text { More information on the model (what, } \\
\text { why, how) }\end{array}$ & {$[30]$} \\
\hline
\end{tabular}




\begin{tabular}{|l|c|}
\hline $\begin{array}{l}\text { Shorten learning curves for novice } \\
\text { engineers }\end{array}$ & {$[22,31]$} \\
\hline Shorten Design cycle time & {$[22,34,35$,} \\
$36,37]$
\end{tabular}

Given the peculiar features of hydrogen combustion, existing gas turbines can be adapted for using hydrogen as a fuel integrating improved burners that are able to work at high temperature. Therefore, one of the major design challenge is related to re-configure existing gas turbines and to integrate new burners/combustor with them. KBE can provide tools to address this challenge with an easier approach. A KBE solution can assist the designer in evaluating the change in the product model based on hydrogen features and also, power generation requirements. For example, a widget can accompany the designers to take the right choices that are automatically translated in changes on the model, to shift in dimensions, tolerances or other geometrical features. Defining rules to guide the assembly of the different parts that refer to a main product structure made of all the possible combinations could be also possible.

In the definition of new burners, KBE can support the check of the points of integration with gas turbines, can support scalability of the dimensions and evaluation of performance. Guiding the designers during the design process, $\mathrm{KBE}$ can provide custom integration of $\mathrm{CAx}$ systems enabling, for example, the automation of the configuration of multiphysics simulations, taking boundary conditions and initial settings directly from the product model, allowing for multiple iterations.KBE can also automate shape optimization, formalizing rules for a geometrical interpretation of simulation results. Furthermore, in HPG systems design, KBE can support the design phase through the implementation of methodologies and tools aimed at integrating and assessing the environmental aspect at early stages of product lifecycle, for example, by providing a precise calculation of $\mathrm{CO} 2$ emissions related to the use of mixedfuels using alternative design configurations of the combustor component.

Most researches have investigated the integration of specific themes as embedding an LCA (Life-Cycle Assessment) instrument and CAD software [41], linking PLM (Product Lifeycle Management) systems and Ecodesign tools and data mapping PLM and LCA databases [42]. KBE can be a good strategy for embedding environmental knowledge (e.g. data from LCA databases) into CAD models thus enabling a concurrent interaction between the design feature and a set of environmental metrics. A KBE application can address diverse product development tasks at once, such as environmental performance indicators (e.g. material recovery, remanufacturing, environmental regulations, economic metrics). The application can suggest how these indicators varied based on design decisions.

\section{Conclusion}

KBE for HPG systems is a widely explored topic in the literature. literature general analysis revealed that there is a large number of studies addressing the use of KBE for gas turbines and burners design but no one of these was in the hydrogen field.

This paper fills this gap by investigating the $\mathrm{KBE}$ concept for generic gas turbines and burners to build lead guidelines for HPG systems as well. The proposed results provide a preliminary contribution to the state of art of HPG systems design by KBE and want to support the discussion about the use of purposely set up IT solutions (such as KBE) aimed at improving design tasks of gas turbines and burners of HPG systems.

Future research can consider the contribution of this study, as a preliminary reference to address innovative solutions for the design stage of HPG systems. Managers and product designers can consider future application of $\mathrm{KBE}$ in their activities in collaboration with the IT staff that can support the source code development. Theoretician can study KBE methods and tools for more efficient and sustainable gas turbines and burners of HPG systems.

\section{References}

1. Y. Matsuo, S. Endo, Y. Nagatomi, Y. Shibata, R. Komiyama, and Y. Fujii, Energy, 165, 1200 1219, (2018).

2. D. J. Goldmeer, GE Power, GEA33861, (2019).

3. K. Inoue, K. Miyamoto, S. Domen, I. Tamura, T. Kawakami, and S. Tanimura, Mitsubishi Heavy Industries Technical Review, 55, 6, (2018).

4. Ansaldo Energia, PowerGeneration News, 2, 10 12, (2018).

5. M. R. Bothien, A. Ciani, J. P. Wood, and G. Fruechtel, J. Eng. Gas Turbines Power, 141,( 2019).

6. M. Grieves, Product Lifecycle Management: Driving the Next Generation of Lean Thinking. (New York: McGraw-Hill, 2006).

7. C. Danjou, J. Le Duigou, and B. Eynard, Int. J. Comput. Integr. Manuf., 30, 995-1009, (2017).

8. A. Corallo, M. Marra, and C. Pascarelli, Aerospace, 6, 41-58, (2019).

9. G. La Rocca and M. van Tooren, Adv. Eng. Inform., 26, 157-158, (2012).

10. D. E. Calkins, N. Egging, and C. Scholz, Int J Eng Ed, 16,21-38, (2000).

11. M. Stokes, Managing Engineering Knowledge: MOKA Methodology for Knowledge Based Engineering Applications. (Wiley Publishing,Inc, 2001).

12. A. H. Van Der Laan and M. J. Van Tooren, $J$. Aircr., 42, 1605-1613, (2004).

13. G. La Rocca, Adv. Eng. Inform., 26, 159-179, (2012).

14. C. B. Chapman and M. Pinfold, Knowl.-Based Syst., 12,. 257-267, (1999). 
15. S. Cooper, I.S. Fan, and G. Li, Achieving Competitive Advantage through KnowledgeBased Engineering p. 21

16. H. T. Dinh, Improving product design phase for engineer to order (ETO) product with knowledge base engineering (KBE), ( 2015).

17. J. Pokojski, S. Fukuda, and J. Salwiński, Eds., New World Situation: New Directions in Concurrent Engineering: Proceedings of the 17th ISPE International Conference on Concurrent Engineering, (2010).

18. P. Bermell-Garcia and I.-S. Fan, J. Prod. Lifecycle Manag.,3,3-20, (2008).

19. D. S. Darai, S. Singh, and S. Biswas, Int. J. Comput. Sci. Inf. Technol, 1, 230-234, (2010).

20. A. Bryman and E. Bell, Business Research Methods, (Oxford University Press, 2015).

21. C. Angelo, C. A. Maria, D. V. Vito, L. Mariangela, and M. Manuela, IEEE Trans. Eng. Manag., 1-13, (2021).

22. H. Ram and S. Krumdieck, GRC Transactions, 42. (2018) .

23. W. Guo, J. Wen, H. Shao, and L. Wang, $A d v$. Mech. Eng., 7, (2015).

24. M. Gessel, M. Pfitzner, and R. Eggels, ASME Turbo Expo 2015: Turbine Technical Conference and Exposition, (2015).

25. H. Xie and W. Zeng, Adv. Mater. Res., vol. 1030, 1342-1347, (2014).

26. C. Küstner, T. Breitsprecher, and S. Wartzack, Proceedings of the International Conference on Engineering Design, ICED, 5, 81-90, (2013).

27. I. Sanya, E. Shehab, D. Lowe, M. Maksimovic, and A. Al-Ashaab, Improving Complex Systems Today, London, , 285-292. (2011).

28. R. Jiang, D.-H. Zhang, and W.-H. Wang, “ Hangkong Dongli XuebaoJournal Aerosp. Power, 25, 1061-1067, (2010).

29. D. Cooper and G. La Rocca, 7th AIAA ATIO Conf, 2nd CEIAT Int'l Conf on Innov and Integr in Aero Sciences, 17th LTA Systems Tech Conf; followed by 2nd TEOS Forum, (2007).

30. T. Guo, H.-L. Yang, and S.-G. Tong, J. Harbin Inst. Techno., 38, 1809-1812, (2006).
31. P. J. Röhl, R. M. Kolonay, M. J. Paradis, and M. W. Bailey, ASME 2001 International Design Engineering Technical Conferences and Computers and Information in Engineering Conference" 789-798 (2001).

32. S. Huang, X. Hao, and M. Benjamin, J. Intell. Manuf., 12, 377-391, (2001).

33. P. Roehl, R. Kolonay, R. Irani, M. Sobolewski, K. Kao, and M. Bailey, 8th Symposium on Multidisciplinary Analysis and Optimization, (2000).

34. J. Marra, ASME 1995 International Gas Turbine and Aeroengine Congress and Exposition, (1995).

35. M. Saxena and R. K. Irani, Concurr. Eng., 2, 4557, Mar. (1994).

36. M. Saxena and K. Irani Rohinton, Mech. Eng., vol. 115, 84-90, (1993).

37. M. Saxena and R. K. Irani, International Design Engineering Technical Conferences and Computers and Information in Engineering Conference, 97645, 385-395. (1993).

38. K. Kessel-Hunter, Society of Manufacturing Engineers. AUTOFACT89 conference, 22, (1989).

39. T. Capozzi, ASME Power Conference, 41820, 1107-1114, (2005).

40. M. Hobday, Res. Policy, 26, 689-710, (1998).

41. H. Ostad-Ahmad-Ghorabi, D. Collado-Ruiz, and W. Wimmer, Proc. ICED 09 17th Int. Conf. Eng.,7 301-310, (2009).

42. J.-P. Theret, D. Evrard, F. Mathieux, Y. Le Guern, and P. Chemla, EnviroInfo2011. Workshop: "Trends in IT for Life Cycle Assessment”, 799-808, (2011) 